\title{
Studies of the immunoglobulin-producing cells of the human intestine: the defunctioned bowel
}

\author{
S S WIJESINHA AND H W STEER* \\ From the Nuffield Department of Surgery, University of Oxford, John Radcliffe Hospital, Headington, Oxford
}

SUMMARY An indirect immunoperoxidase method was used to visualise immunoglobulincontaining cells in the large intestinal mucosa of 10 children who had defunctioning colostomies. Intestine deprived of its usual exposure to intraluminal antigens contained less immunocytes per unit area than intestinal mucosa subjected to normal stimulation by dietary and microbial antigens. These findings substantiate in man the conclusion based on observations made on animals that continued mucosal exposure to antigenic stimulation is necessary for the existence of an adequate population of intestinal immunocytes.

Great emphasis is placed on the importance of continued mucosal exposure to antigenic stimulation for the maintenance of a secretory immune response in the intestine. ${ }^{12}$ Most of the supporting evidence has come from animal experiments.

The present paper describes immunohistochemical studies on a group of patients who had undergone defunctioning colostomy, resulting in the distal segment of gut being deprived of the normal flow of intestinal contents. An attempt was made to compare the numbers of immunoglobulin-containing cells in the proximal (exposed) and distal (defunctioned) colon.

\section{Methods}

\section{PATIENTS}

The group of 10 patients studied ranged in age from 2 months to 13 years. A proximal colostomy had been raised in each of these children, two to 11 months previously in the course of treatment of neonatal necrotising enterocolitis or Hirschsprung's disease. Clinicopathological information about these patients is given in Table 1.

Biopsies were taken from the site of the colostomy which had been placed in the normal colon at a distance from the site of pathology. Mucosal tissue resected from both proximal (exposed) and distal (defunctioned) colon during the process of closing the colostomy was obtained. In this manner, each patient acted as his own control.

\footnotetext{
*Present address: Southampton General Hospital, Southampton.

Received for publication 17 August 1981
}

\section{HISTOLOGY}

The biopsies were fixed in formol sublimate, ${ }^{3}$ dehydrated in a graded series of ethanol solutions, cleared in chloroform, and embedded in paraffin wax. Sections were cut at 3-5 $\mu \mathrm{m}$ and stained by the indirect immunoperoxidase method. ${ }^{4}$

The antisera used (rabbit anti-human $\operatorname{IgA}$, rabbit anti-human IgM, rabbit anti-human IgG, and peroxidase-conjugated swine anti-rabbit IgG) were obtained commercially (DAKO-immunoglobulins Ltd, Denmark). These antisera have been used extensively for immunoperoxidase staining and found to be efficacious. ${ }^{5}$ The stained sections were examined at $\times 400$ magnification using a transmitted light microscope with a grid eyepiece. The number of peroxidase stained cells was counted and expressed as 'number per $\mathrm{mm}^{2}$ of lamina propria'; earlier studies had shown that this technique of 'area counting' for the colon gives results that correlate closely with those obtained by 'point counting' (submitted for publication).

\begin{tabular}{ccccc} 
Table 1 & \multicolumn{4}{c}{ Clinicopathological information about patients } \\
\hline Patient & $\begin{array}{l}\text { Age } \\
\text { (months) }\end{array}$ & Sex & Diagnosis & $\begin{array}{l}\text { Months since } \\
\text { raising } \\
\text { colostomy }\end{array}$ \\
\hline 1 & 2 & M & Necrotising enterocolitis & 1 \\
2 & 2 & F & Necrotising enterocolitis & 2 \\
3 & 5 & M & Hirschsprung's disease & 4 \\
4 & 10 & M & Hirschsprung's disease & 8 \\
5 & 10 & M & Hirschsprung's disease & 10 \\
6 & 13 & M & Hirschsprung's disease & 3 \\
7 & 49 & M & Hirschsprung's disease & 4 \\
8 & 81 & M & Hirschsprung's disease & 24 \\
9 & 95 & M & Hirschsprung's disease & 8 \\
10 & 161 & M & Hirschsprung's disease & 11 \\
\hline
\end{tabular}


STATISTICS

Wilcoxon's rank sum test for paired samples was used.

\section{Results}

Conventional transmitted light microscopy revealed for both groups of patients a normal mucosa and submucosa without apparent infiltration of inflammatory cells (Figs. 1 and 2), irrespective of the primary pathology of the patients. IgA-containing cells were found in the lamina propria of all the colonic biopsies, whether they were from functioning or defunctioned bowel. In eight of the 10 patients, the defunctioned colon had a reduced population of IgA immunocytes when compared with the functioning colon (Table 2). Wilcoxon's rank sum test for paired samples showed this result to be statistically significant $(P<0.02)$.

The lamina propria in 19 of the 20 colonic biopsies contained IgM immunocytes. The number of IgM-containing cells (mean $64.3, \mathrm{SEM}=24.8$ ) in functioning colon was less than the number of $\operatorname{IgA}$-containing cells

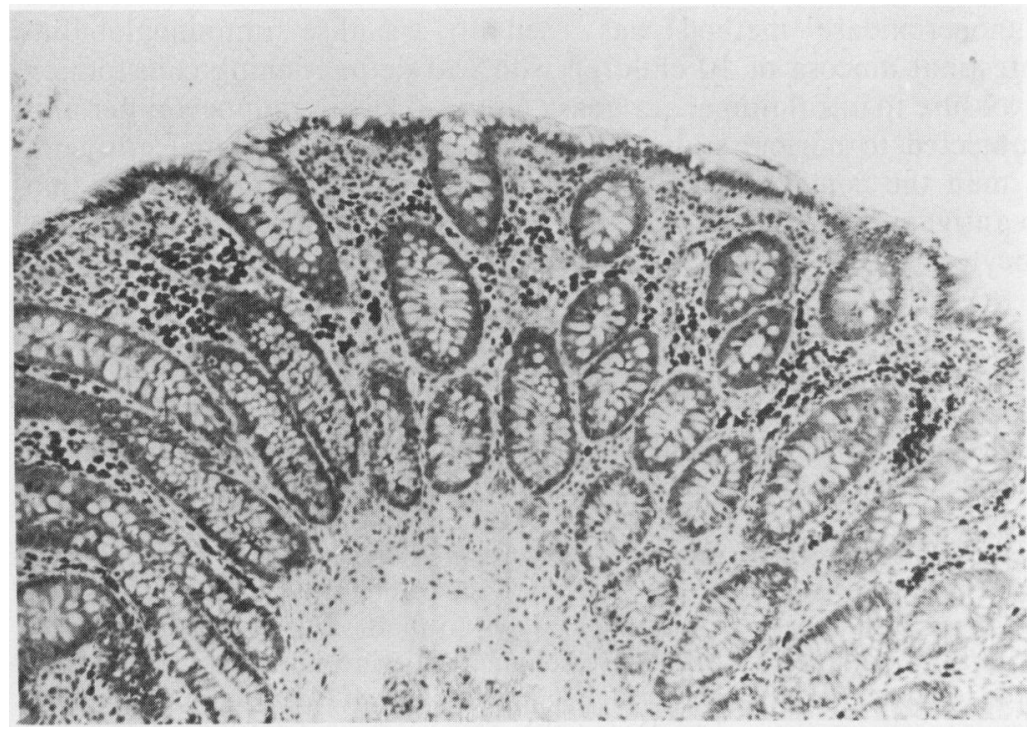

Fig. 1 Section of colon ('functioning' bowel) stained for IgA-containing cells. Immunoperoxidase, $\times 100$.
Fig. 2 Section of colon ('defunctioned' bowel) stained for IgA-containing cells. Immunoperoxidase, $\times 100$.

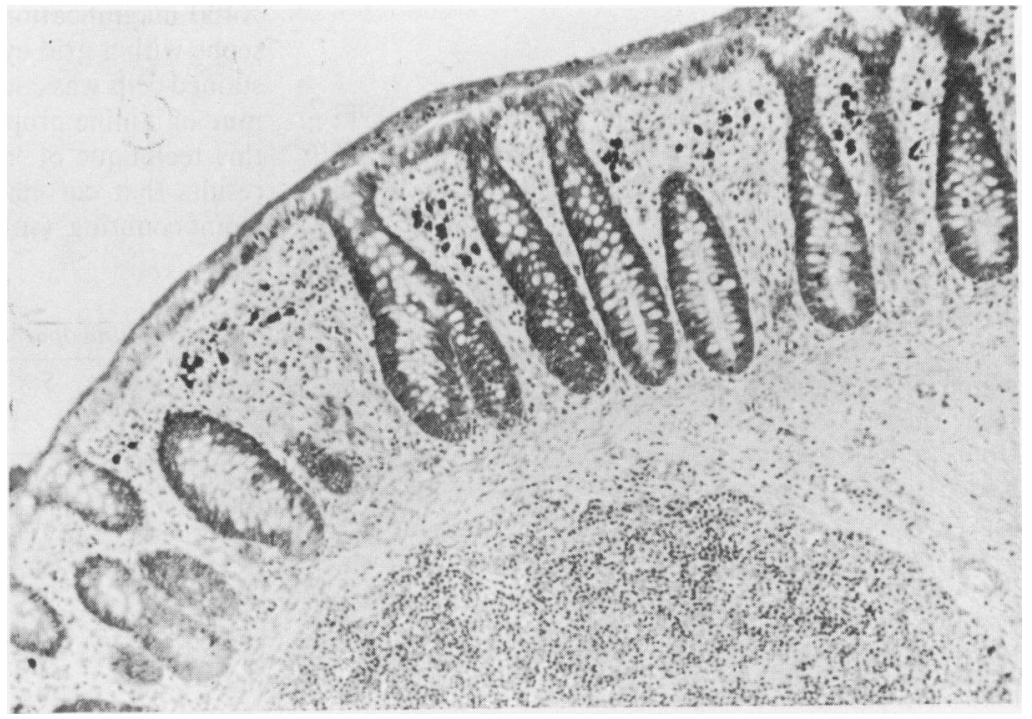


$($ mean $=544 \cdot 1$, SEM $=119 \cdot 8)$. The same pattern was seen in the defunctioned colon, where the numbers of immunocytes were as follows:

$\operatorname{IgM}-$ mean $=29.3, \quad$ SEM $=8.8$

$\operatorname{IgA}-$ mean $=315.4, \quad$ SEM $=63.3$

When compared with the proximal functioning colon, there were less IgM immunocytes in the defunctioned colon in nine of the ten patients studied (Table $3)$. This result was significant $(P<0.02)$ when subjected to Wilcoxon's rank sum test.

No correlation was seen between the numbers of IgA immunocytes and the numbers of IgM immunocytes, in either functioning or defunctioned colon. IgG-containing cells were sparse in all the specimens of colonic mucosa studied.

Table 2 IgA Immunocyte counts in exposed and defunctioned colon

\begin{tabular}{lcc}
\hline Patient & \multicolumn{2}{c}{ Immunocyte density $\left(\right.$ cells $\left./ \mathrm{mm}^{2}\right)$} \\
\cline { 2 - 3 } & Exposed colon & Defunctioned colon \\
\hline 1 & 243 & 60 \\
2 & 65 & 4 \\
3 & 798 & 144 \\
4 & 331 & 372 \\
5 & 187 & 158 \\
6 & 385 & 440 \\
7 & 843 & 551 \\
8 & 611 & 414 \\
9 & 564 & 388 \\
10 & 1414 & 623 \\
\hline
\end{tabular}

Table 3 IgM Immunocyte counts in exposed and defunctioned colon

\begin{tabular}{lcc}
\hline Patient & \multicolumn{2}{c}{ Immunocyte density $\left(\right.$ cells $\left./ \mathrm{mm}^{2}\right)$} \\
\cline { 2 - 3 } & Exposed colon & Defunctioned colon \\
\hline 1 & 29 & 24 \\
2 & 46 & 10 \\
3 & 279 & 32 \\
4 & 32 & 13 \\
5 & 20 & 14 \\
6 & 38 & 48 \\
7 & 125 & 102 \\
8 & 20 & 14 \\
9 & 51 & 36 \\
10 & 1 & 0 \\
\hline
\end{tabular}

\section{Discussion}

It has been known for many years that antigen does have a regulating role in the localisation of immunocytes in the intestine. Ogra and Karzon ${ }^{6}$ used polio vaccine to inoculate 12 patients who had defunctioning colostomies. Introduction of vaccine into a segment produced a secretory antibody response confined to that segment. They inferred that this response was influenced by the continued presence of the antigen at the mucosal surface.
Similar experiments on sheep ${ }^{7}$ and rats ${ }^{1}$ using small intestinal Thiry-Vella loops confirmed that increased numbers of immunoglobulin-containing cells were found in the loops having intraluminal antigens. Similar numbers of immunocytes were found in the loops exposed to antigenic stimulation as well as the unchallenged loops six hours after cell transfer; examination of the loops a day later, however, revealed that the numbers had increased in the 'exposed' gut, while the intestinal loops lacking antigenic stimulation showed a complete absence of plasma cells.

As a result of these findings, Husband and Gowans ${ }^{1}$ postulated that plasma cell localisation in the intestine occurs in the two phases. The first phase, involving the influx of lymphoblasts from the circulation, is not dependent on the presence of antigen in the gut. However, the second phase, whereby recruitment and differentiation of small lymphocytes as well as proliferation of non-recirculating large lymphocytes occurs, is antigen dependent.

Cebra $e t a l,{ }^{8}$ as a result of their extensive investigations on mice, concluded that the gut-associated lymphoid tissue is perpetually in a primed state, at least with respect to environmental antigenic determinants. Chronic exposure to micro-organisms, plant lectins and other molecules capable of binding to cell membranes is the most effective means of stimulating a secretory IgA response. ${ }^{2}$

The present study confirms that, in man, as in the previous animal experiments, antigenic stimulation of the gut mucosa is necessary for the maintenance of a normal population of immunoglobulin-containing cells. As both 'exposed' and 'non-exposed' colon were taken simultaneously from the same patient, this would negate the effect of any influences such as age, ethnic differences, and unrelated diseases.

The number of IgA or IgM immunocytes in the lamina propria of defunctioned colonic mucosa was not reduced to zero; indeed, in two patients there were more immunoglobulin-containing cells in the distal colonic segment. There are a number of possible explanations for this observation. The colostomy, although intended to be defunctioning, may not have been absolute in this respect. There was no attempt in this study to determine the degree of overspill of antigenic material from the functioning colon to the defunctioned colon. It is also possible that, even if the distal segments were not subjected to the usual flow of dietary antigens, they may have been colonised by intestinal microflora; bacterial culture from the lumen of these segments was not attempted. Finally, it has already been stated that the initial phase of immunocyte localisation in the gastrointestinal mucosa is non-antigenic. ${ }^{1}$ It therefore follows that immunocytes in this phase of localisation would be present in defunctioned colon lacking antigenic stimulation. 
As has been described, ${ }^{96}$ IgA immunocytes far outnumber IgM immunocytes in the intestinal mucosa of the normal child; in the present group of children, ranging in age from 2 months to $13+$ years, the same pattern exists in the histologically normal colon. For both $\operatorname{IgA}$ and IgM immunocytes, however, excluding the mucosa from exposure to antigenic stimulation results in a reduced population of plasma cells.

These findings in man substantiate the relevance of previous results obtained from animal experiments that is, intestine deprived of its usual exposure to intraluminal antigens contains fewer immunocytes than does intestinal mucosa subjected to normal stimulation by dietary and microbial antigens.

We are grateful to Messers Malcolm Gough, Nicholas Dudley, and Harold Nixon for permission to study their patients; also to Mrs. Elena Jeffery for histological assistance, Mr. John Hiles for the photomicrographs, and Miss Angela Munro for secretarial assistance. S S Wijesinha is supported by a Commonwealth Medical Scholarship.

\section{References}

1 Husband AJ, Gowans JL. The origin and antigen-depen- dent distribution of IgA-containing cells in the intestine. $J$ Exp Med 1978; 148:1146-60.

2 Cebra JJ, Crandall CA, Gearhart PJ, Robertson SM, Tseng J, Watson PM. Cellular events concerned with the initiation, expression and control of the mucosal immune response. In: Ogra PL, Dayton D, eds. Immunology of breast milk. New York: Raven Press, 1979.

3 Piris J, Thomas N. A quantitative study of the influence of fixation on immunoperoxidase staining of rectal mucosal plasma cells. J Clin Pathol 1980; 33:361-4.

4 Burns J. Immunohistochemical methods and their application in the routine laboratory. In: Anthony PP, Woolf N, eds. Recent advances in histopathology. No. 10. Edinburgh: Churchill Livingstone, 1978.

5 Mason DY, Sammons R. Alkaline phosphatase and peroxidase for double immunoenzymatic labelling of cellular coristituents. J Clin Pathol 1978; 31:454-60.

6 Ogra PL, Karzon DT. Distribution of poliovirus antibody in serum, nasopharynx and alimentary tract following segmental immunization of lower alimentary tract with poliovaccine. J Immunol 1969; 102:1423-30.

7 Husband AJ, Lascelles AK. The origin of antibody in intestinal secretion of sheep. Aust J Exp Biol Med Sci 1974; 52:791-9.

8 Cebra JJ, Emmons R, Gearhart PJ, Robertson SM, Tseng J. Cellular parameters of the IgA response. Adv Exp Med Biol 1978; 107:19-28.

9 Savilahti E. Immunoglobulin-containing cells in the intestinal mucosa and immunoglobulins in the intestinal juice in children. Clin Exp Immunol 1972; 11:415-25. 